\title{
Produção do algodoeiro em função da salinidade e tratamento de sementes com regulador de crescimento ${ }^{1}$
}

\author{
Cotton yield as a function of salinity and seeds treatment with growth regulator
}

\author{
Francisco de Assis de Oliveira ${ }^{2 *}$, José Francismar de Medeiros ${ }^{2}$, Francisco Ronaldo Alves de Oliveira ${ }^{3}$, Alcione \\ Guimarães Freire ${ }^{3}$ e Leonardo Cirilo da Silva Soares ${ }^{4}$
}

\begin{abstract}
Resumo - Este trabalho foi realizado com o objetivo de avaliar o efeito de diferentes níveis de salinidade da água de irrigação e sementes tratadas com regulador de crescimento na produção do algodoeiro. O delineamento experimental adotado foi inteiramente ao acaso, arranjados em esquema fatorial 5 x 2 com quatro repetições. Os tratamentos resultaram da combinação de cinco níveis de condutividade elétrica da água de irrigação $\left(S_{1}-0,5 ; S_{2}-2,0 ; S_{3}-3,5 ; S_{4}-5,0\right.$ e $S_{5}-6,5$ dS m $\left.{ }^{-1}\right)$ em sementes tratadas e não tratadas com regulador de crescimento. As variáveis avaliadas foram: produção de algodão em caroço, produção de sementes e de fibra, peso de 100 sementes e porcentagem de fibra. Não houve interação entre os níveis de salinidades e as sementes tratadas com regulador de crescimento. Os parâmetros produtivos do algodoeiro são reduzidos com uso de água de salinidade a partir de $3,5 \mathrm{dS} \mathrm{m}^{-1}$, independente das sementes serem tratadas com regulador de crescimento. As características agronômicas: peso de 100 sementes, porcentagem de fibra e produção de algodão em caroço não são influenciadas pelo cloreto de mepiquat. $\mathrm{O}$ tratamento das sementes com regulador de crescimento não afeta o efeito adverso da salinidade.
\end{abstract}

Palavras-chave - Algodão-cultivo. Estresse salino. Cloreto de mepiquat.

\begin{abstract}
This study was conducted to evaluate the effect of different salinity levels of irrigation water and seed treated with growth regulator on the yield of cotton. It was used an entirely statistical randomized design, in a factorial scheme $5 \times 2$, with four replications. The treatments resulted from the combination of four salinity levels of irrigation water $\left(\mathrm{S}_{1}-0.5 ; \mathrm{S}_{2}-2.0 ; \mathrm{S}_{3}-3.5\right.$; $\mathrm{S}_{4}-5.0$ and $\mathrm{S}_{5}-6.5 \mathrm{dS} \mathrm{m}^{-1}$ ) in treated and untreated seeds with growth regulator. The variables were: production of cotton, seed and fiber, 100 seed weight and percentage of fiber. There was not interaction between salinity levels and seed treated. The parameters of cotton production are reduced with the use of water salinity from $3.5 \mathrm{dS} \mathrm{m}^{-1}$, independent of seed treated or not with growth regulators. Agronomic traits 100 seed weight, percentage of fiber and seed cotton production are not influenced by mepiquat chloride. The seed treatment with growth regulator do not affects the adverse effect of salinity.
\end{abstract}

Key words - Crop-cotton. Saline stress. Mepiquat chloride.

\footnotetext{
*Autor para correspondência

${ }^{1}$ Recebido para publicação em 23/11/2010; aprovado em 09/08/2011

Pesquisa financiada pelo convênio FINEP/FAPERN/PRODECOT e UFERSA

${ }^{2}$ Departamento de Ciências Ambientais e Tecnológicas/UFERSA, Mossoró-RN, Brasil, 59.625-900, thikaoamigao@ufersa.edu.br; jfrancismar. rn@uol.com.br

${ }^{3}$ Departamento de Ciências do Solo/Campus do Pici/Bloco 807, UFC, Fortaleza-CE, Brasil, 60.455-760, ronaldoindep@yahoo.com.br; alcionegf@hotmail.com

${ }^{4}$ Departamento de Produção Vegetal/ESALQ, Piracicaba-SP, Brasil, 13.418-900, leonardowsoares@ibest.com.br
} 


\section{Introdução}

O algodoeiro herbáceo (Gossypium hirsutum L. var. latifolium Hutch.) é uma das principais culturas exploradas no Brasil, cultivada em mais de quinze Estados. Ao decorrer de 10 anos, entre 1998 e 2008, o Brasil passou de importador para exportador de algodão, ocupando a quinta colocação dentre os países que mais produzem a cultura no mundo, respondendo por $5,7 \%$ da produção (COSTA et al., 2008).

A cotonicultura tem se destacado como uma das atividades agrícolas de maior importância para o agronegócio brasileiro, tal fato deve-se ao crescente desenvolvimento de pesquisas objetivando o aumento da eficiência produtiva, com destaque para estudos envolvendo a fisiologia das plantas.

A irrigação é uma das tecnologias de maior influência no desenvolvimento e produção das culturas, minimizando os efeitos nocivos das secas periódicas e da irregularidade das chuvas, condições edafoclimáticas típicas de regiões áridas e semiáridas. Silva e Rao (2005) afirmam que a retomada da produção no Nordeste do Brasil está condicionada à aplicação de novas tecnologias, principalmente às relacionadas ao uso eficiente da água que provocará benefícios ambientais e redução nos custos de produção.

O uso de águas salinas na irrigação para produção vegetal é um desafio que vem sendo superado com sucesso, em diversas partes do mundo, graças à utilização de espécies tolerantes e à adoção de práticas adequadas de manejo das culturas, do solo e da água de irrigação (RHOADES et al., 2000).

Esses estudos enfocam respostas das plantas às condições adversas do ambiente de cultivo, principalmente quando o cultivo é realizado em solo salinizado, ou a irrigação é realizada utilizando águas com elevada concentrações de sais solúveis. Apesar de o algodoeiro ser considerado uma cultura tolerante á salinidade (TAIZ; ZEIGER, 2009), estudos têm observado efeitos deletérios do estresse salino sobre o desempenho produtivo do algodoeiro, sendo essa resposta variada em função do genótipo e do manejo adotado (JÁCOME et al., 2003).

Dentre estes estudos, o uso de regulador de crescimento aparece como uma tecnologia promissora e já bastante empregada entre os produtores. No algodoeiro, sua aplicação visa reduzir a altura da planta, para torná-la mais compacta e facilitar o uso de defensivos e a colheita mecânica (LAMAS et al., 2000). Com o uso de cloreto de mepiquat, são obtidas plantas com alteração na partição da biomassa, inibindo o crescimento de determinadas partes e estimulando outras, o que confere maior eficiência às plantas, em especial maior tolerância ao estresse hídrico (COTHREN; OOSTERHUIS, 1993).
Na literatura são encontrados inúmeros trabalhos desenvolvidos com aplicação de regulador de crescimento sob diferentes formas, podendo ser aplicado via foliar, em dose única ou parcelada, ou via tratamento de sementes (NAGASHIMA et al., 2005; NAGASHIMA et al., 2009; ZANQUETA et al., 2004), apresentando resultados que evidenciam o uso do regulador via tratamento de sementes, metodologia esta que tem a vantagem de apresentar menor risco de contaminação ambiental.

Apesar do uso crescente de regulador de crescimento na cultura do algodoeiro, ainda são escassos estudos sobre a resposta da cultura à aplicação deste produto em plantas cultivadas sob condições de estresse. Tendo em vista a necessidade do uso de águas salinas na irrigação e do crescente uso de regulador de crescimento na cultura do algodoeiro, este trabalho foi desenvolvido com o objetivo de avaliar o efeito da salinidade sobre a produção de plantas em função do tratamento de sementes com cloreto de mepiquat.

\section{Material e métodos}

O experimento foi conduzido no período de janeiro a abril de 2009 em casa de vegetação, do Departamento de Ciências Vegetais da Universidade Federal Rural do SemiÁrido (UFERSA), localizado no município de Mossoró, RN. Com as coordenadas geográficas de 5 $5^{\circ} 11^{\prime} 31^{\prime \prime}$ de latitude Sul e $37^{\circ} 20^{\prime} 40^{\prime \prime}$ de longitude Oeste de Greenwich e altitude média de $18 \mathrm{~m}$.

A estrutura da casa de vegetação é de aço galvanizado, sendo as partes laterais e frontais confeccionadas com tela negra com 50\% de sombreamento. A cobertura é em arco tipo túnel, medindo 7,0 m de largura e 18,0 m de comprimento, com manta de polietileno de baixa densidade, transparente, com $0,15 \mathrm{~mm}$ de espessura.

O delineamento experimental utilizado foi inteiramente ao acaso, com os tratamentos distribuídos em esquema fatorial $5 \times 2$, com quatro repetições, sendo a unidade experimental representada por um vaso com capacidade para $12 \mathrm{dm} 3$, contendo uma planta. Os tratamentos resultaram da combinação de cinco níveis de condutividade elétrica da água de irrigação $\left(\mathrm{S}_{1}-0,5 ; \mathrm{S}_{2}-2,0\right.$; $\mathrm{S}_{3}-3,5, \mathrm{~S}_{4}-5,0$ e $\mathrm{S}_{5}-6,5 \mathrm{dS} \mathrm{m} \mathrm{m}^{-1}$ ) com o tratamento ou não das sementes com regulador de crescimento (Sementes tratadas com cloreto de mepiquat; Sementes não tratadas).

As sementes foram tratadas através de embebição em solução de cloreto de mepiquat na concentração de 7,5\% (v/v) por um período de 12 horas, em seguida, as sementes foram secas à sombra e conservadas em sacos de papel até a semeadura (NAGASHIMA et al., 2007), que foi realizada cinco dias após o tratamento. 
Foram semeadas cinco sementes da cultivar Delta Opal em cada vaso, e, cinco dias após a emergência das plântulas, realizou-se o desbaste deixando em cada vaso a plântula mais vigorosa. Utilizou-se esta cultivar devido à mesma ser responsiva à aplicação deste regulador de crescimento, conforme observado por Bogiani e Rosolem (2009), bem como por apresentar tolerância à salinidade, segundo Furtado et al. (2007).

Os diferentes níveis de salinidade foram obtidos pela dissolução de cloreto de sódio $(\mathrm{NaCl})$ em água proveniente do sistema de abastecimento do campus da UFERSA $\left(\mathrm{S}_{1}\right)$, ajustando-se com condutivímetro de bancada, com correção automática de temperatura. A água utilizada para representar o nível de salinidade de $0,5 \mathrm{dS} \mathrm{m}^{-1}$, e na obtenção das demais salinidade apresentou as seguintes características químicas: $\mathrm{pH}=8,30 ; \mathrm{CE}=0,50 \mathrm{dS} \mathrm{m}^{-1}$; $\mathrm{Ca}^{2+}=3,10 ; \mathrm{Mg}^{2+}=1,10 ; \mathrm{K}^{+}=0,30 ; \mathrm{Na}^{+}=2,30 ; \mathrm{Cl}^{-}=1,80$; $\mathrm{HCO}_{3}{ }^{-}=3,00 ; \mathrm{CO}_{3}^{2-}=0,20\left(\mathrm{mmol}_{\mathrm{c}} \mathrm{L}^{-1}\right)$.

Foi utilizado material de solo do tipo Latossolo Vermelho Amarelo de textura arenosa, coletado na camada de 0-30 m de profundidade. O material coletado foi seco ao ar e posteriormente peneirado em malha de 2,0 mm. Antes do acomodamento do solo nos vasos, foi retirada uma subamostra para ser submetida às análises físico-químicas, cujos resultados são apresentados na Tabela 1 .

O solo foi peneirado e acondicionado em vasos plásticos com capacidade para $12 \mathrm{dm}^{3}$, deixando-se cerca de $2 \mathrm{~cm}$ entre a superfície do solo e a borda superior do vaso para facilitar a irrigação, evitando possível transbordamento da água durante as irrigações, que foram realizadas manualmente, utilizando uma proveta graduada $(500 \mathrm{~mL})$. O material de solo foi acondicionado em cada vaso de forma que, após o término do enchimento, fosse obtida densidade semelhante àquela obtida na análise física.

Foi realizada adubação de fundação com N, Pe K, aplicando-se 100; 200 e $100 \mathrm{mg} \mathrm{dm}^{-3}$ de solo, utilizando os seguintes fertilizantes: uréia para fornecimento de
$\mathrm{N}$, fosfatomonoamônico para o fornecimento de $\mathrm{P}$ e de $\mathrm{N}$, e cloreto de potássio para K. Os fertilizantes foram diluídos em água e aplicando-se em cada vaso volume suficiente para elevar o teor de água do solo até a umidade correspondente à máxima capacidade de retenção de água do material do solo (capacidade de vaso).

No período entre a semeadura e o desbaste a irrigação foi realizada utilizando-se água proveniente do sistema de abastecimento do campus da UFERSA $\left(\mathrm{S}_{1}\right)$. No dia seguinte após o desbaste a irrigação foi realizada utilizando água com diferentes níveis salinos, de acordo com os tratamentos utilizados.

O suprimento hídrico das plantas foi realizado com frequiência de uma irrigação diária até os 30 dias após a semeadura (DAS), enquanto que do $31^{\circ}$ DAS até a colheita foi adotada a freqüência de duas aplicações por dia, uma pela manhã e outra à tarde, de acordo com a necessidade da cultura. Em cada irrigação foi aplicado um volume de água suficiente para elevar a umidade do solo próximo da máxima capacidade de retenção de água no solo, sendo o volume de água aplicado determinado por meio de pesagens diárias.

A colheita foi realizada manualmente e numa única vez, aos 110 dias após a semeadura. Após a colheita os capulhos foram acondicionados em sacolas plásticas previamente identificadas e em seguida transportados para o Laboratório de Irrigação e Salinidade do Departamento de Ciências Ambientais e Tecnológicas.

Os capulhos de cada planta foram pesados e em seguida realizado o deslintamento manual para separação da fibra dos caroços. Os componentes avaliados foram: produção de algodão em caroço, produção de sementes, produção de fibras, peso de 100 sementes e a porcentagem de fibra no capulho. Os dados obtidos foram submetidos à análise de variância e as médias resultantes do tratamento de semente comparadas entre si aplicando-se o teste de Tukey ao nível de 5\%. Em seguida, realizou-se a análise de regressão para as variáveis que houve efeito significativo para condutividade elétrica da água de irrigação.

Tabela 1 - Características físicas e químicas do solo utilizado no experimento

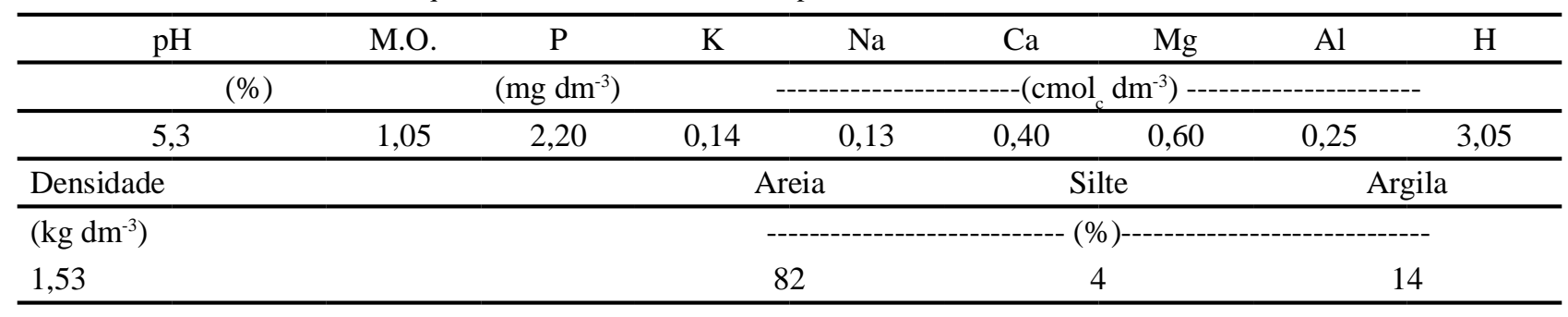




\section{Resultados e discussão}

A partir da análise de variância (TAB. 2), verificou-se que não houve interação significativa entre salinidade da água de irrigação e tratamento de sementes com cloreto de mepiquat para todas as características avaliadas $(p>0,05)$, indicando que o efeito da salinidade independe da aplicação de cloreto de mepiquat. Desta forma, o efeito dos fatores estudados sobre os parâmetros produtivos do algodoeiro foram avaliados isoladamente. Foi observado efeito significativo da salinidade da água de irrigação sobre o número de capulhos (NCAP), produção total de algodão em caroço (PRODTOT), produção de fibras (PRODFIB), produção de sementes (PRODSEM) e peso de 100 sementes (P100SEM) ao nível de $1 \%$, não sendo, no entanto, observado efeito da salinidade sobre porcentagem de fibra (\%FIB) $(\mathrm{p}>0,05)$. Com relação ao efeito do tratamento das sementes com cloreto de mepiquat, foi verificada resposta significativa para PRODFIB, P100SEM e \%FIB ( $p<0,01)$, não sendo constatada resposta significativa para as demais variáveis $(\mathrm{p}>0,05)$.

\section{Salinidade da água de irrigação}

$\mathrm{O}$ número de capulhos por planta (NCAP) foi reduzido linearmente em resposta ao aumento da salinidade da água de irrigação $(\mathrm{p}<0,01)$, sendo observada redução em cerca de 0,46 capulhos por planta $(6,46 \%)$, por aumento unitário da salinidade, e perda total de $38,79 \%$ nas plantas irrigadas com água de salinidade de $6,5 \mathrm{dS} \mathrm{m}^{-1}$, em comparação com aquelas irrigadas com água de menor salinidade. Apesar dos dados obtidos se ajustarem ao modelo linear, pode-se verificar que o efeito mais deletério ocorreu a partir da salinidade de $3,5 \mathrm{dS} \mathrm{m}^{-1}$ (FIG. 1). Estes resultados estão próximos aos obtidos por Souza Júnior et al. (2005), que verificaram redução no NCAP na ordem de 6,55\% por aumento unitário da salinidade. Jácome et al. (2003), avaliaram a resposta de cinco genótipos de algodão sob estresse salino e constataram que todos esses materiais tiveram NCAP afetados pela salinidade, sendo verificado redução de $42,54 \%$ na salinidade de $6,0 \mathrm{dS} \mathrm{m}^{-1}$.

Figura 1 - Número de capulhos do algodoeiro irrigado com água de diferentes níveis de salinidade

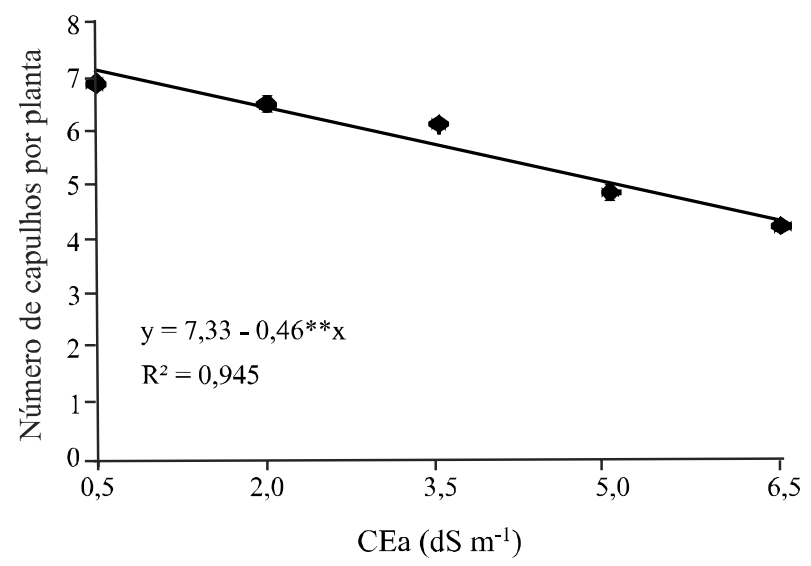

Um dos principais efeitos da salinidade sobre o rendimento das plantas está relacionado com a redução do número de frutos, comportamento esse encontrado para outras espécies de interesse agronômico, como amendoim (CORREIA et al., 2009), melão (MEDEIROS et al., 2008), pepino (MEDEIROS et al., 2009), entre outras.

Tabela 2 - Resumo da análise de variância para número de capulhos (NCAP), produção total (PRODTOT), produção de fibras (PRODFIB), produção de sementes (PRODSEM), peso de 100 sementes (P100SEM) e porcentagem de fibra (\%FIB) do algodoeiro em função da salinidade da água de irrigação e do tratamento de sementes com cloreto de mepiquat

\begin{tabular}{lccccccc}
\hline \multirow{2}{*}{ Fontes de variação } & \multirow{2}{*}{ GL } & \multicolumn{7}{c}{ Quadrados médios } \\
\cline { 3 - 7 } & & NCAP & PRODTOT & PRODFIB & PRODSEM & P100SEM & $\%$ FIB \\
\hline Salinidade (Sal) & 4 & $9,96^{* *}$ & $279,96^{* *}$ & $32,76^{* *}$ & $109,65^{* *}$ & $13,79^{* *}$ & $14,31^{\text {ns }}$ \\
Linear & 1 & $37,81^{* *}$ & $987,01^{* *}$ & $108,11^{* *}$ & $400,51^{* *}$ & $51,20^{* *}$ & $27,61^{\text {ns }}$ \\
Quadrático & 1 & $1,08^{\text {ns }}$ & $114,01^{* *}$ & $21,44^{* *}$ & $31,08^{*}$ & $2,29^{\text {ns }}$ & $2,29^{\text {ns }}$ \\
Cloreto de mepiquat $(C M)$ & 1 & $2,02^{\text {ns }}$ & $14,4^{\text {ns }}$ & $6,4^{* *}$ & $1,23^{\text {ns }}$ & $19,60^{* *}$ & $90,00^{* *}$ \\
Sal x CM & 4 & $0,59^{\text {ns }}$ & $3,21^{\text {ns }}$ & $0,46^{\text {ns }}$ & $2,91^{\text {ns }}$ & $1,54^{\text {ns }}$ & $39,69^{\text {ns }}$ \\
Resíduo & 28 & 1,23 & 3,67 & 0,18 & 4,37 & 3,18 & 21,47 \\
CV (\%) & - & 18,53 & 10,00 & 5,79 & 17,61 & 18,21 & 12,03 \\
\hline
\end{tabular}

* $\mathrm{e}^{* *}$ Significativo a 0,05 e a 0,01 de probabilidade, respectivamente; $\mathrm{ns}$ - não significativo pelo teste $\mathrm{F}$ 
A produção de algodão em caroço (PRODTOT) foi afetada pelo aumento da condutividade elétrica da água de irrigação, sendo observado efeito deletério a partir de 3,5 $\mathrm{dS} \mathrm{m}^{-1}$, ajustando-se os dados a modelos polinomiais de segundo grau ( $\mathrm{p}<0.01)$, conforme mostrado na Figura 2. A análise da equação ajustada permitiu estimar pequena perda na PRODTOT entre as salinidade de 0,5 e $3,5 \mathrm{dS} \mathrm{m}^{-1}$, na ordem de $12,62 \%$, enquanto que, comparando-se a PRODTOT obtida na salinidade de $6,5 \mathrm{dS} \mathrm{m}^{-1}$, com a obtida na salinidade de $3,5 \mathrm{dS} \mathrm{m}^{-1}$, estima-se redução de $52,23 \%$.

Figura 2 - Produção de algodão em caroço irrigado com água de diferentes níveis de salinidade

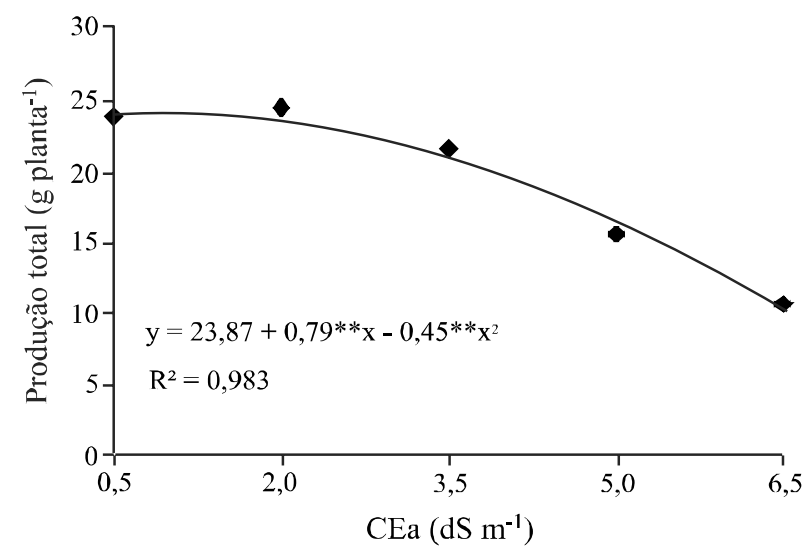

Conforme descrito, a produção do algodoeiro foi reduzida significativamente a partir da CEa de $3,5 \mathrm{dS} \mathrm{m}^{-1}$, atribuindo-se a esse valor como a salinidade limiar da cultura, com redução em cerca de $18,41 \%$ na produção relativa por incremento unitário da condutividade elétrica da água de irrigação (FIG. 3). Esses resultados estão de acordo com os obtidos por Cavalcante et al. (2005), que trabalhando com duas cultivares de algodão, CNPA-7H e colorido marrom BRS-200, sob irrigação com águas salinizadas, verificaram que o rendimento de ambas as cultivares foi comprometido com salinidade da água superior a $3,1 \mathrm{dS} \mathrm{m}^{-1}$.

Considerando que o material de solo utilizado neste trabalho apresentou textura média, e que a relação entre a salinidade da água (CEa) e do extrato de saturação (CEes) para este tipo de textura do solo é de 1,5 (MAAS; HOFFMAN, 1977), a condutividade elétrica limiar, considerando o extrato de saturação, poderá ser estimada em 5,25 dS m ${ }^{-1}\left(1,5 \times 3,5 \mathrm{dS} \mathrm{m}^{-1}\right)$, ficando assim abaixo da salinidade limiar conforme a literatura (AYERS; WESTCOT, 1999), que é de 7,7 dS m${ }^{-1}$, o que evidencia que o efeito da salinidade pode ser variável em função das
Figura 3 - Produção relativa de algodão em caroço irrigado com água de diferentes níveis de salinidade

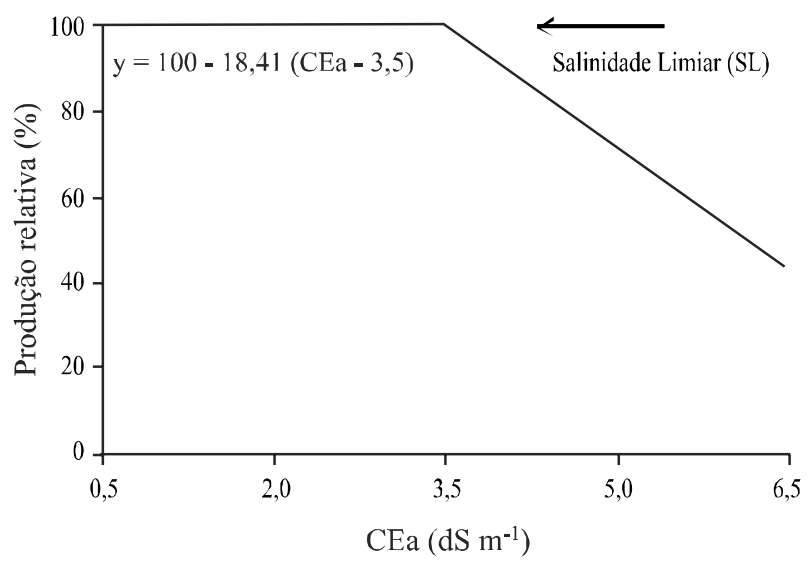

condições ambientais e do material genético utilizado. A redução na produção do algodoeiro em consequiência do aumento da $\mathrm{CEa}$ pode ser atribuída à menor absorção de água pelas plantas sob estresse hídrico. Desta forma, a redução na absorção de água pelas plantas pode ter acarretado uma diminuição na produção das plantas, conforme resultados obtidos por Cordão Sobrinho et al. (2007).

Avaliando as produções de fibra (PRODFIB) e de sementes (PRODSEM) isoladamente, verifica-se comportamento semelhante entres estas variáveis, bem como a PRODTOT, com redução significativa a partir da CEa 3,5 dS m m $^{-1}$, ajustando-se a equação de regressão quadrática para ambos os casos ( $\mathrm{p}<0,01)$. A PRODFIB (FIG. 4) foi menor que a PRODSEM (FIG. 5) em todos os níveis de salinidade, sendo obtidos, na salinidade de 3,5 dS m$~ m^{-1}$, valores de 8,28 e 12,94 $\mathrm{g} \mathrm{planta}^{-1}$, respectivamente. Os menores valores foram observados nas plantas irrigadas com água de salinidade $6,5 \mathrm{dS} \mathrm{m}^{-1}$, com reduções totais de 49,10\% para PRODFIB (FIG. 4) e de 50,82\% para PRODSEM (FIG.5), em comparação com os valores obtidos na salinidade de $3,5 \mathrm{dS} \mathrm{m}{ }^{-1}$. Silva et al. (2008) trabalhando com duas cultivares de mamona, verificaram redução em cerca de $96,80 \%$ na produção de sementes para as plantas irrigadas com água de salinidade 4,7 dS m${ }^{-1}$, em comparação com a salinidade de $0,7 \mathrm{dS} \mathrm{m}^{-1}$.

Os resultados obtidos no presente trabalho demonstram que o feito da salinidade sobre a produção do algodoeiro está relacionadocomareduçãodocapulhoporinteiro, evidenciando assim que a análise da produção de capulhos é suficiente na avaliação da produção da cultura sob estresse salino. Jácome et al. (2003) trabalhando com diferentes genótipos de algodoeiro também observaram redução nos parâmetros de produção em reposta ao aumento da salinidade.

O peso de 100 sementes (P100SEM) variou de 11,43 a 8,18 g para 0,5 e $6,5 \mathrm{dS} \mathrm{m}^{-1}$, respectivamente, 
Figura 4 - Produção de fibras do algodoeiro irrigado com água de diferentes níveis de salinidade

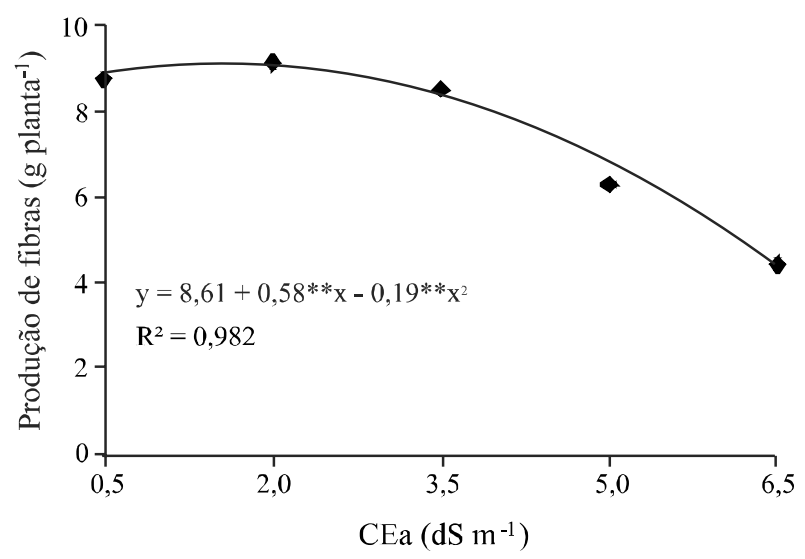

e foi afetado linearmente $(\mathrm{p}<0,01)$ e negativamente pela salinidade da água de irrigação, apresentando redução de $0,54 \mathrm{~g} 100 \mathrm{SEM}$ por aumento unitário da condutividade elétrica, e redução total na maior salinidade (6,5 dS m $\left.{ }^{-1}\right)$ de 28,46\% em comparação com o resultado obtido com a salinidade de $0,5 \mathrm{dS} \mathrm{m} \mathrm{m}^{-1}$ (FIG. 6). Esses resultados divergem dos obtidos por Jácome et al. (2003), que não observaram efeito significativo da salinidade sobre P100SEM. No entanto, estudos têm encontrado redução na massa das sementes em função da salinidade para diversas espécies, como mamona (SILVA et al., 2008) e amendoim (CORREIA et al., 2009).

Segundo Rhoades et al. (2000), a salinidade afeta não apenas o desenvolvimento, mas também a produção das culturas, efeito que se manifesta principalmente na redução da população e do desenvolvimento dos frutos, com sintomas similares ao do estresse hídrico; em geral, a salinidade do solo, causada pela irrigação com água salina

Figura 6 - Peso de 100 sementes do algodoeiro irrigado com água de diferentes níveis de salinidade

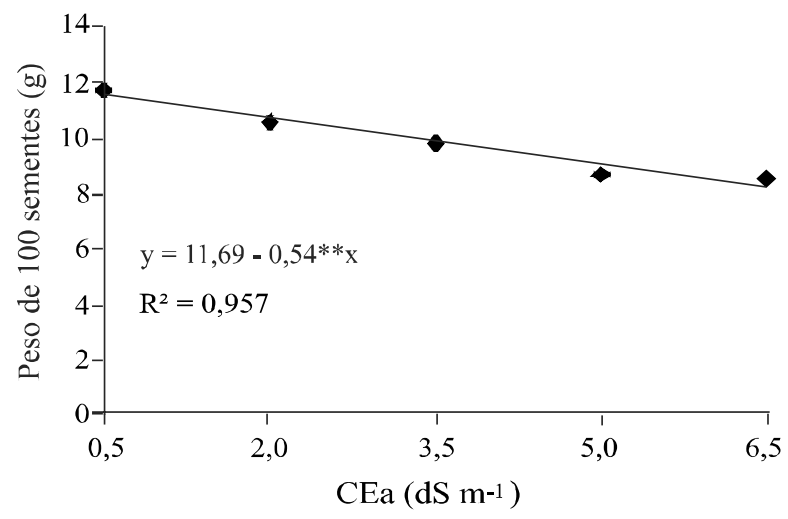

Figura 5 - Produção de sementes do algodoeiro irrigado com água de diferentes níveis de salinidade

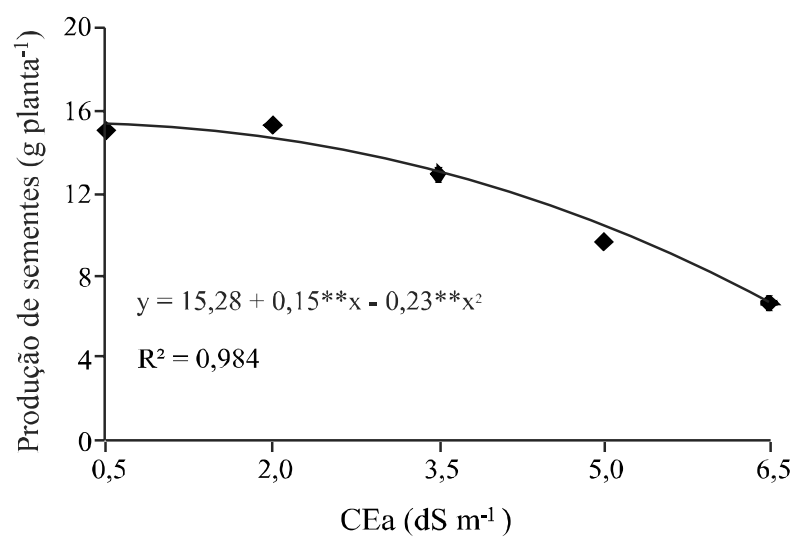

como pela combinação de fatores água, solo e manejo das culturas, pode resultar em aumento nos dias para colheita, redução no número de frutos, no peso dos frutos e sementes, influenciando, diretamente a produção.

Não houve efeito da salinidade sobre a porcentagem de fibra (FIB), sendo obtidos valores variando de 36,6 a 40,0\% para as salinidade de 0,5 e $3,5 \mathrm{dS} \mathrm{m}^{-1}$, com média entre os níveis salinos de 38,5\% (FIG. 7). Este índice de fibra está próximo ao obtido por Jácome et al. (2003) que avaliando o desempenho produtivo de genótipos de algodoeiro sob estresse salino, encontraram que esses três parâmetros produtivos são características intrínsecas de cada genótipo, não sendo afetados pela salinidade, resultados semelhantes aos obtidos no presente trabalho.

\section{Regulador de crescimento}

Não houve resposta significativa para sementes tratadas com cloreto de mepiquat para NCAP, PRODTOT

Figura 7 - Porcentagem de fibra em capulhos do algodoeiro irrigado com água de diferentes níveis de salinidade

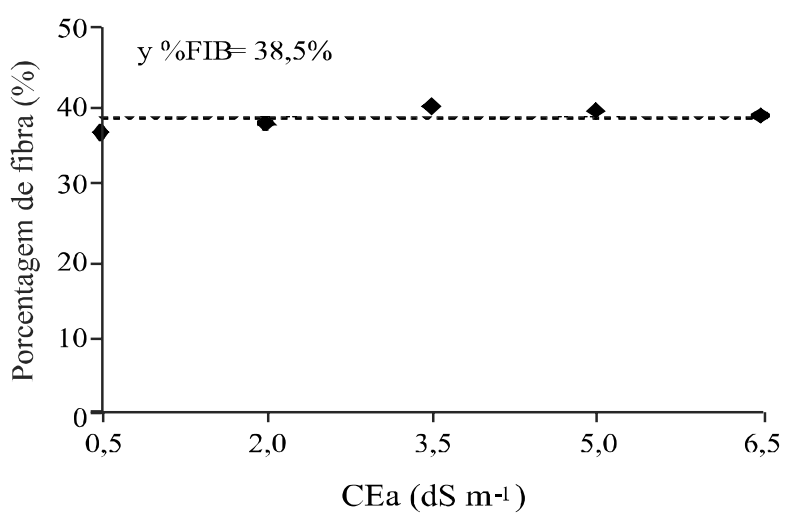


e PRODSEM ( $p>0,05$ ), sendo obtidos valores médios de 5,7 capulhos por planta, 19,15 e 11,88 $\mathrm{g}_{\text {planta }}{ }^{-1}$, respectivamente (FIG. 8A, 8B e 8D). Foram observadas diferenças significativas para PRODFIB e P100SEM ao nível de $1 \%$ de probabilidade, e ao nível de $5 \%$ para $\%$ FIB. O tratamento de sementes com cloreto de mepiquat proporcionou maior P100SEM, com peso superior em $15,4 \%$ em relação às sementes não tratadas. Em contrapartida, as sementes não tratadas proporcionaram maior PRODFIB $(11,4 \%)$ e \%FIB $(8,1 \%)$ (FIG. 8C, 8E e 8F). Na literatura são encontrados resultados divergentes sobre os parâmetros produtivos do algodão sob tratamentos de sementes com cloreto de mepiquat.

Nagashima et al. (2007) avaliaram a resposta do algodoeiro ao tratamento de sementes com cloreto de mepiqual, e não observaram efeito da embebição de sementes com cloreto de mepiquat sobre a produção de algodão em caroço, no peso de capulho, e no número de maçãs por planta. Cordão Sobrinho et al. (2007) avaliaram o efeito do regulador de crescimento e lâminas de irrigação, e também não observaram efeito significativo do CM

Figura 8 - Valores médios obtidos para número de capulhos (A), produção total (B), produção de fibras (C), produção de sementes (D), peso de 100 sementes (E) e porcentagem de fibra (F) do algodoeiro em função do tratamento de sementes com cloreto de mepiquat
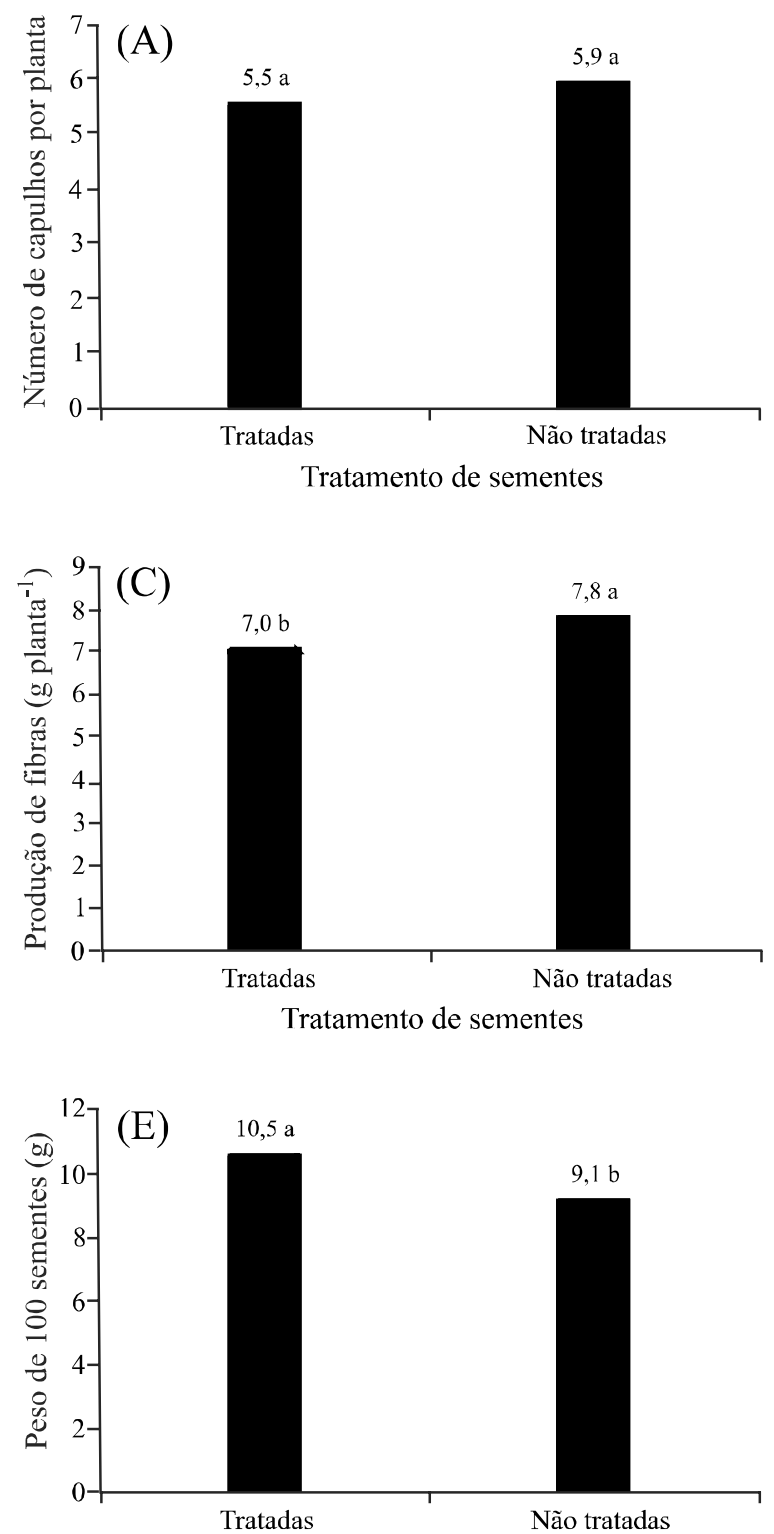

Tratamento de sementes
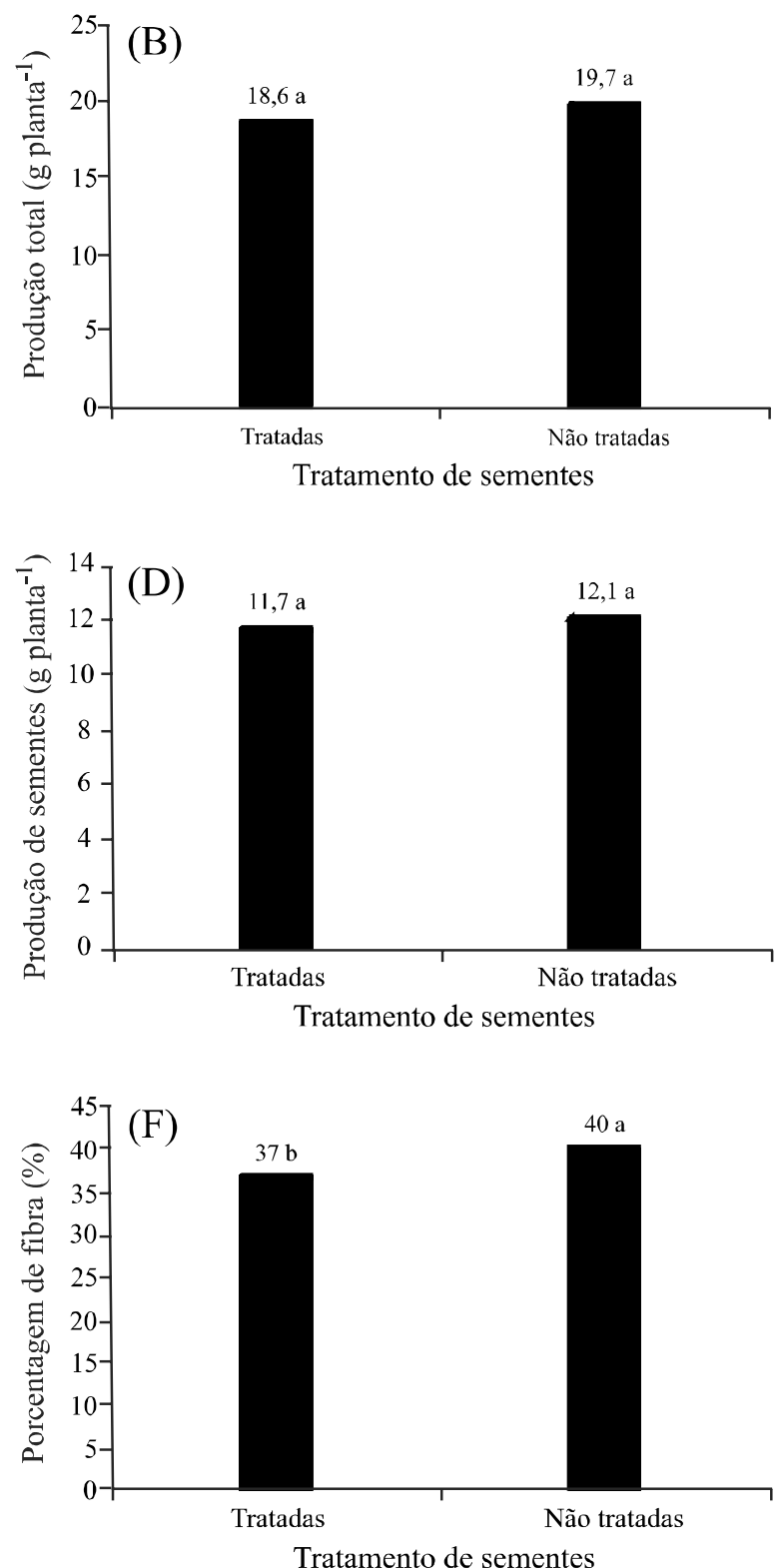
sobre o rendimento do algodoeiro. No entanto, Teixeira et al. (2008) verificaram efeito significativo e positivo da aplicação de regulador de crescimento sobre massa de 100 sementes e produtividade do algodão em caroço.

Apesar das plantas provenientes de sementes tratadas com CM apresentarem menores valores para PRODFIB e \%FIB, o uso do CM promove modificações morfofisiológicas importantes para o manejo da cultura. De forma geral os benefícios da aplicação de reguladores de crescimento em cultivos de algodão se devem, principalmente, à redução do crescimento vegetativo e maior equilíbrio entre as partes vegetativa e reprodutiva, conforme referido por Athayde e Lamas (1999), facilitando o manejo da cultura.

Outro ponto importante para adoção do uso desta tecnologia na cultura do algodoeiro está relacionado com o efeito do CM sobre o desenvolvimento vegetativo das plantas, interferindo no metabolismo vegetal e resultando em plantas mais compactas e mais uniformes, o que possibilita o cultivo mais adensado (NAGASHIMA et al., 2009; ZANQUETA et al., 2004), resultando consequentemente em maior produção de fibra por unidade de área, aumentando assim a eficiência do uso da terra.

\section{Conclusões}

1.O efeito do tratamento das sementes com regulador de crescimento (cloreto de mepiquat) e da irrigação com água salina ocorreram de forma isolada;

2. Os parâmetros produtivos do algodoeiro são reduzidos com uso de água com condutividade elétrica a partir de $3,5 \mathrm{dS} \mathrm{m}^{-1}$, independente do tratamento das sementes com regulador de crescimento;

3.O tratamento das sementes com cloreto de mepiquat afetou o peso de 100 sementes, produção e a porcentagem de fibras do algodoeiro.

\section{Referências}

ATHAYDE, M. L. F.; LAMAS, F. M. Aplicação de cloreto de mepiquat no algodoeiro. Pesquisa Agropecuária Brasileira, v. 34, n. 03, p. 369-375, 1999.

AYERS, R. S.; WESTCOT, D. W. A qualidade de água na agricultura. 2. Ed. Campina Grande: UFPB, 1999. 153 p. (FAO. Estudos Irrigação e Drenagem, 29).

BOGIANI, J. C.; ROSOLEM, C. A. Sensibilidade de cultivares de algodoeiro ao cloreto de mepiquat. Pesquisa Agropecuária Brasileira, v. 44, n. 10, p. 1246-1253, 2009.

CAVAlCANTE, I. H. L. et al. Crescimento e produção de duas cultivares de algodão irrigadas com águas salinizadas.
Revista Brasileira de Engenharia Agrícola e Ambiental, v. 09, p. 108-111, 2005. Suplemento.

CORDÃO SOBRINHO, F. P. et al. Crescimento e rendimento do algodoeiro BRS-200 com aplicações de cloreto de mepiquat e lâminas de irrigação. Revista Brasileira de Engenharia Agrícola e Ambiental, v. 11, n. 03, p. 284-292, 2007.

CORREIA, K. G. et al. Crescimento, produção e características de fluorescência da clorofila $a$ em amendoim sob condições de salinidade. Revista Ciência Agronômica, v. 40, n. 04, p. 514-521, 2009.

COSTA, A. C. P. et al. Algodão. In: Agronegócio brasileiro, São Paulo: Sonopress Gráfica, 2008. p. 24-29.

COTHREN, J. T.; OOSTERHUIS, D. M. Physiological impact of plant growth regulators in cotton. In: BELTWIDE COTTON PRODUCTION RESEARCH CONFERENCES, 1993, Dallas, Texas. Proceedings... Memphis: National Cotton Council, 1993. p. 128-132.

FURTADO, R. F. et al. Efeito da salinidade na germinação de sementes de algodão. Revista Ciência Agronômica, v. 38, n. 02, p. 224-227, 2007.

JÁCOME, A. G. et al. Comportamento produtivo de genótipos de algodão sob condições salinas. Acta Scientiarum Agronomy, v. 25, n. 01, p. 187-194, 2003.

LAMAS, F. M.; ATHAYDE, M. L. F.; BANZATTO, D. A. Reações do algodoeiro CNPA - ITA 90 ao cloreto de mepiquat. Pesquisa Agropecuária Brasileira, v. 35, n. 03, p. 507-516, 2000.

MAAS, E. V.; HOFFMAN, G. J. Crop salt tolerance - current assessment. Journal of Irrigation and Drainage Division, v. 103, p. 115-134, 1977.

MEDEIROS, J. F.; DIAS, N. S.; BARROS, A. D. Manejo da irrigação e tolerância do meloeiro a salinidade da água de irrigação. Revista Brasileira de Ciências Agrárias, v. 03, n. 03, p. 242-247, 2008.

MEDEIROS, P. R. F.; DUARTE, S. N.; DIAS, C. T. S. Tolerância da cultura do pepino a salinidade em ambiente protegido. Revista Brasileira de Engenharia Agrícola e Ambiental, v. 13, n. 04, p. 406-410, 2009.

NAGASHIMA, G. T. et al. Desenvolvimento de plantas de algodão provenientes de sementes embebidas em cloreto de mepiquat. Pesquisa Agropecuária Brasileira, v. 40, n. 09, p. 943-946, 2005.

NAGASHIMA, G. T. et al. Embebição de sementes com cloreto de mepiquat no crescimento e produção do algodoeiro. Ciência e Agrotecnologia, v. 31, n. 04, p. 1027-1034, 2007.

NAGASHIMA, G. T. et al. Cloreto de mepiquat via embebição de sementes e aplicação foliar em algodoeiro em espaçamento ultraestreito. Revista Ciência Agronômica, v. 40, n. 04, p. 602-609, 2009.

RHOADES, J. P.; KANDIAH, A.; MASHALI, A. M. Uso de águas salinas na produção agrícola. Campina Grande: UFPB, 2000. $117 \mathrm{p}$. 
SILVA, B. B.; RAO, T. V. R. The CWSI variations of a cotton crop in a semi-arid region of Northeast Brazil. Journal of Arid Environments, v. 62, n. 04, p. 649-659, 2005.

SILVA, S. M. S. et al. Desenvolvimento e produção de duas cultivares de mamoneira sob estresse salino. Revista Brasileira de Engenharia Agrícola e Ambiental, v. 12, n. 04, p. 335-342, 2008.

SOUZA JÚNIOR, S. P. et al. Germinação, crescimento e produção do algodoeiro colorido BRS Verde sob estresse salino. Revista Brasileira de Engenharia Agrícola e Ambiental, v. 09, p. 236-241, 2005. Suplemento.
TAIZ, L.; ZEIGER, E. Plant physiology. 3. ed. Porto Alegre: Artmed, 2009. 719. p.

TEIXEIRA, I. R.; KIKUTI, H.; BORÉM, A. Crescimento e produtividade de algodoeiro submetido a cloreto de mepiquat $\mathrm{e}$ doses de nitrogênio. Bragantia, v. 67, n. 04, p. 891-897, 2008.

ZANQUETA, R. et al. Modos de aplicação de regulador de crescimento com diferentes densidades de plantas em cultivares de algodão herbáceo (Gossypium hirsutum L. var. latifolium Hutch.). Acta Scientiarum Agronomy, v. 26, n. 01, p. 97-105, 2004. 